How to cite this article:

Md Salleh A. S., Romli F., Mat.Salleh K., Adnan, A. (2020). Role of internal halal committee in ensuring business sustainability: The case of a multinational slaughter house. Journal of Business Management and Accounting, 10(2), 57-65.

\title{
Role of Internal Halal Committee in Ensuring Business Sustainability: The Case of a Multinational Slaughter House
}

\author{
Anis Shuhaiza Md Salleh"a, Fariza Romli ${ }^{\text {, }}$, Khuzaimah Mat Salleh ${ }^{\mathrm{c}}$ \& \\ Adziah Adnan ${ }^{\mathrm{d}}$ \\ a, b, c School of Law, College of Law, Government and International Studies, \\ Universiti Utara Malaysia, Sintok, Kedah \\ d Jimat Jaya Sdn. Bhd., Sungai Petani, Kedah
}

Received: $11 / 5 / 2020$

Revised: $9 / 8 / 2020$

Accepted: $12 / 82020$

Published: $15 / 11 / 2020$

\begin{abstract}
For an industry, business sustainability is a critical aspect to be addressed by the company to remain relevant in an ever competitive market demand. In doing so, one of the strategies that can be taken is through adhering to all laws and legal requirements, particularly on halal aspect. The establishment of the Internal Halal Committee (IHC) is part of the requirement stipulated by the Malaysia Guidelines on Halal Assurance System 2011 (HAS 2011) and Manual Procedure for Malaysia Halal Certification (Third Revision) 2014 (MPPHM 2014). These laws must be read together with standards, Fatwa decisions, and regulations which are enforced pertaining to Malaysia Halal Certification. The law requires the establishment of IHC together with the appointment of a halal executive, supervisor, and also checkers in order to ensure that products are in accordance with standards prescribed by the law and Shariah principles in Malaysia. By adopting a case study approach involving a multinational slaughter house, this article highlights the practice taken up by Jimat Jaya Sdn. Bhd. The study employed interviews and non-participatory observation for data collection. It was revealed that strict legal requirements imposed by the government on halal products and compliance
\end{abstract}

* Corresponding Author

E-mail: shuhaiza@uum.edu.my, arfariza@uum.edu.my, khuzai@uum.edu.my, adziah@jjsb.sp@ gmail.com 
by the company have helped the company to gain more confidence from its existing and potential customers in relation to their products, hence ensuring sustainability of the business in the market.

Keywords: Chicken slaughter, internal halal committee, Malaysia halal certification, multinational company, slaughter house

\subsection{Introduction}

Ensuring sustainability and remaining relevant in a competitive market today is getting more challenging as industries, particularly halal food, are growing rapidly. Indeed, the halal food market is nowadays immense (Abdullah, Zubairi, \& Ghani, 2007). In Malaysia, the government has taken steadfast steps to position Malaysia as a halal hub in producing halal products (Abdul Talib \& Mohd Ali, 2009). Halal slaughtered chicken is among the food industries that is closely monitored by the government through its laws and enforcement. The law categorises the company into big or multinational, medium or small scale industry by looking at its production per day. Specifically, according to Appendix 2 of the Manual Procedure for Malaysia Halal Certification (Third Revision) 2014 or known as Manual Prosedur Pensijilan Halal Malaysia (Semakan Ketiga) 2014 (MPPHM 2014), a big chicken slaughter company refers to a firm with a production output of more than 10,000 slaughtered chicken per day, while a medium company ranges from 3,000 to 10,000 chicken per day, and a small company has between 1 to 2,999 slaughtered chicken per day.

More importantly, ensuring the halal aspect for a large number of products is not an easy task without a good monitoring system and management. Failure to observe halal aspects in production may affect the quality of the product or more seriously may make the product non-halal (Razaly \& Zakaria, 2018). An officer from the Kedah Islamic Religious Affairs Department (JHEAIK) clarified that the existence of Internal Halal Committee (IHC) in a company, which works hand-in-hand with the Department of Islamic Development Malaysia (JAKIM)/State Islamic Religious Affairs Department (JAIN), has the responsibility of ensuring halal products to be produced more efficiently, responsibly, and confidently. JAKIM plays a very important role to protect Muslim consumers in Malaysia and it has always been JAKIM's responsibility to assure the people to seek for halal products as urged by Shariah (JAKIM, 2011). For the purpose of halal certification, JAKIM has to ascertain the halal status of the product at every stage and at every process involved, by carrying out an official site inspection on plants, purposely to examine how the halal status of raw material is maintained and monitored at all times (Rosyadah, personal communication, August 7, 2019). The establishment of the IHC is part of the requirement stipulated by the Malaysia Guidelines on Halal 
Assurance System 2011 (HAS 2011) and MPPHM 2014. Religious officers from JAKIM/JAIN will observe the process of slaughtering from beginning to end in ensuring that all processes are in compliance with the principles of Shariah and legal requirements (JAKIM, 2015).

\subsection{Methodology}

This study was qualitative in nature by employing a case study method on a multinational company, categorised as a slaughter house. Apart from using library based materials, which included primary and secondary sources, this paper highlights the practice taken up by Jimat Jaya Sdn. Bhd. (JJSB) in establishing its own IHC, and to be in compliance with the law. JJSB was chosen on the basis that this company is multinational and produces standard halal chicken products throughout Malaysia, in which legal requirements pertaining to halal must strictly be complied with. Interviews were conducted with factory manager and halal executives of JJSB. They were done in order to get in-depth information on practical application of laws, experiences, procedures, problems, and practices taken up by JJSB. Non-participatory observational method was also used in observing the slaughter process carried out by the company from start to finish. Additionally, interviews were also carried out with two officers from Halal Management Section, Kedah Islamic Religious Affairs Department (JHEAIK) to collaborate and validate the data. The researchers used descriptive and critical data analysis. The findings of the study were significant in clarifying doubts and increasing understanding on legal requirements and implementation in the slaughter industry, particularly a large-scale company.

\subsection{Background of the Company}

Jimat Jaya Sdn. Bhd. (JJSB) was selected for this case study based on a selection criteria. The selection was made because the company was among the most popular company that produces halal chicken products distributed throughout Peninsular Malaysia. The company is a non- bumiputra company and had started its operations in 2013 at Sungai Petani, Kedah. Being a subsidiary company to CAB Cakaran Corporation Berhad (CAB) - a public listed company on the Main Board of Bursa Malaysia Securities Berhad-JJSB has been involved in integrated poultry business for processing fresh, chilled and frozen carcasses, offal, and chicken parts (Cab.com, 2020).

JJSB is located at Plot 21-24, Kawasan Industri Ringan Bukit Makmur, Sungai Lalang, Bedong, Kedah Darul Aman. The JJSB organisation chart consists of the Chief Executive Director and Executive Director as the top management of JJSB. There are 
various departments in JJSB, namely the Department of Accounts, Logistics, Human Resource, Store, Maintenance, Halal, Quality Assurance and Quality Control (QA/QC), Information Technology (IT), as well as the Department of Purchasing and Production. With enhanced marketing strategies, quality control, technological advances, experience and expertise, collaborative activities, as well as efficient management of product distribution, JJSB had successfully penetrated the food industry both domestically and globally. In addition, by having good Standard Operating Procedures (SOPs) and a quality assurance system, the factory manager had confirmed that JJSB gain trust and confidence from its regular and potential customers from all over the country, which consists of hypermarkets, hotels, fast food outlets, agencies, and individuals (Azizul, personal communication, July 17, 2019).

Emphasising on the Islamic concept in its production, where halal slaughtered chicken is its priority, Azizul (personal communication, July 17, 2019) mentioned that:

The company emphasised on cleanliness and purity of its products to ensure that the products were in line with the regulations enforced by JAKIM of which the products of JJSB were guaranteed halal and had been certified by JAKIM. Together with that, JJSB also required its staff to attend internal and external courses organised by JAKIM, Department of Veterinary Services (DVS) and Ministry of Health (MOH) to enhance the workers' educational input and skills. Besides, they also attended courses organised by the Malaysian certified body namely SGS (Malaysia) Sdn. Bhd. as well as by the Standard and Industrial Research Institute of Malaysia (SIRIM) in order to enhance their management skills and kept abreast with the latest trends and developments in the market.

Furthermore, the interview revealed that the company had received various recognitions and certifications (Azizul, personal communication, July 17, 2019). Apart from receiving the HALAL certification from JAKIM, JJSB had also received the recognitions from SGS (Malaysia) Sdn. Bhd., certifying that the company had reached the standard of Food Safety System Certification (FSSC 22000) and Food Safety Management System (ISO 22000:2005) ISO 9001:2008 (SGS), applicable to processing of fresh, chilled, and frozen whole dressed chicken. The company also received recognition from SGS (Malaysia) Sdn. Bhd. on the Hazard Analysis Critical Control Point (HACCP) and Good Manufacturing Practice (GMP), which are internationally recognized food safety systems together with the Quality Assurance Programme (QAP) certification and the Veterinary Health Mark (VHM) certification by the DVS. In addition, the company owns the Skim Pensijilan Makanan Selamat Tanggungjawab Industri (MeSTI) certification from the Ministry of Health which acknowledges that the processing premise is in good and safe condition according to the rules laid down by the Ministry. 
JJSB managed to obtain the Platinum Shauffmantz Veritas (PSV) EMS (ISO 14001) through the audited certification body pertaining to the environmental monitoring system. This included activities ranging from receiving live birds (raw material) to finish products being transferred out from the cold room onto the lorry for distribution. More importantly, most of the suppliers for JJSB, which supply the live birds to the company, are recognized as having Good Veterinary Hygiene Practice (GVHP) or Skim Amalan Ladang Ternakan (SALT) as certified by DVS.

\subsection{Legal Requirements on the Establishment of IHC and Its Roles}

Section 3 of the Descriptions (Definition of Halal) Order 2011 defines the term halal or other usable terms used to denote halal food or goods to range from the consumption, components, preparation, or process to storage that must be in accordance to or permissible by the Shariah and Fatwa. This includes the slaughtering process of chicken by a company that is categorized as a slaughter house. Moreover, the MPPHM 2014 defines a slaughter house as a premise or place, which is used to slaughter animals for commercial purposes. The requirements imposed by the law on the management of the company, though similar to a medium scale, is slightly different with those applicable to a small scale company. For instance, the management of a multinational and medium scale company are required to establish the IHC, appoint a Muslim halal executive or a Muslim halal supervisor, a Muslim halal checker at the very least, and two slaughterers at the very least, of whom the number must be proportionate with the birds to be slaughtered. Meanwhile, these requirements are not imposed on a small scale company. Under this category, the information provided by the factory manager indicated that JJSB is a big company as its production has reached 35,000 to 40,000 slaughtered chicken per day (Azizul, personal communication, July 17, 2019).

Apart from that, the Guidelines for Halal Assurance Management System of Malaysia Halal Certification by JAKIM (HAMS Guidelines) is also an important piece of procedural document that needs to be observed by the company. Generally, the HAMS Guidelines spell out that the role of the IHC is to be responsible for developing, monitoring, and controlling the halal assurance system to ensure its effectiveness. The IHC meeting is expected to involve all internal halal committee members to discuss issues related to the development, implementation, maintenance, and review of the Halal Assurance Management System. Together with that, the HAMS Guidelines also prescribe that the IHC shall consist of at least four members where two of them must be Muslim at the management level, with one person shall be responsible for purchasing or procurement. The employee who is responsible for managing halal matters for the company shall be the coordinator of the IHC. For a slaughterhouse, the halal supervisor shall be a member of the IHC. The committee members must be knowledgeable and well 
trained in halal standard and halal certification requirements. This is mainly because all the conditions and methods of slaughtering an animal must be meticulously observed for the sole purpose of making its meat fit for human consumption, particularly by Muslims (Mian \& Munir, 2018). The management of the company shall ensure that the terms of reference of the IHC are fully established and the effectiveness of the IHC in implementing the Halal Assurance Management system shall be reviewed periodically. According to Azizul (personal communication, July 17, 2019):

In practice, the review process will be done at least once every year. On the other hand, an immediate review is needed if there are changes in the IHC itself, changes to the monitoring schedules or changes in the operations and/or supply chain.

Likewise, the officer at JHEAIK mentioned that in implementing the Halal Assurance Management System, there are certain important principles for the IHC to observe, such as the determination of halal critical points in which all possible sources of contamination (halal critical point) throughout the supply chain that lead to noncompliance to halal standard requirements (Muhamad Hafiz, personal communication, August 7, 2019). In relation thereto, the IHC shall develop appropriate flow charts which consists of all steps involved in the entire supply chain process. The flow charts can be used as tools for the IHC to identify potential halal threats and implement appropriate control measures to ensure compliance with Shariah requirements. Risk management may include identifying the risk, measuring the level of risk, monitoring to facilitate effective risk management, and controlling recurrences of non-compliance risk (Shafii \& Md Zain, 2015). Based on an interview with the halal executive of JJSB, he confirmed that corrective actions have to be developed whenever monitoring indicates non-compliance occurring, so it is important that the IHC establishes and maintains effective documentation and record keeping systems to provide evidence of conformity to the requirements and effective implementation of Halal Assurance Management System. More importantly, application for the renewal of Halal Certification shall be made by the IHC every year. An internal audit on daily production and quality assurance processes are to be executed by IHC before the application for renewal is made to JAKIM. The report from the IHC is used as a basis for the application of halal certification from JAKIM (Mohd Zulkhairi, personal communication, July 17, 2019).

Talking on the establishment of the IHC by JJSB, Mohd Zulkhairi (personal communication, July 17, 2019) mentioned that:

The IHC is headed by the factory manager as the advisor, followed by the chairman, who is a halal executive of the company. In particular, the chairman of the IHC, must ensure that sufficient and required training is 
given to the staff in order to ensure the standards and laws as prescribed by JAKIM have been properly complied with. In addition to that, the chairman is the one who would identify any deficiency in practices or non-compliance of standards/laws and provide recommendations for rectification thereto.

Most importantly, the chairman is a liaison officer, who connects and coordinates with JAKIM/JHEAIK and suppliers on all halal related matters. He must provide documents for halal certification applications and renewal, technical assistance for compliance with halal certification requirements, and to ensure slaughterers have completed slaughter training provided by JAKIM/JHEAIK. The interview with the officer from JHEAIK showed that in practice, periodic monitoring will be done at least twice a year by JHEAIK on the slaughter houses that have Certificate of Halal Certification Malaysia (CHCM). As for non-certified slaughter houses, JHEAIK can only act based on reports received from the public (Rosyadah, personal communication, August 7, 2019). According to the Guideline for Halal Assurance Management System of Malaysia Halal Certification, periodic assessment shall be conducted in ensuring relevant employees have received required training and knowledge. This would enable them to effectively perform their roles and fulfil responsibilities in complying with halal standard and halal certification requirements. In short, through examination of documents relating to SOP that is practised and observation of the slaughtering process conducted by JJSB, the researchers found that strict legal requirements imposed on halal aspect and commitment by the company to abide the law have helped the firm to sustain in the competitive market.

\subsection{Recommendations}

Based on the above discussion, it can be safely said that the IHC carries important responsibilities in monitoring, controlling, improving, and preventing any noncompliance in producing halal products. Therefore, JJSB or any big company must have sufficient numbers of IHC staff to maintain quality and efficient division of work. Since the MPPHM 2014 also requires that the IHC consist of at least four members, it is recommended that the company may need to hire more members depending on the size of its production.

The company also needs to provide more financial allocation for adequate and continuous training on the Malaysian Halal Standards and Certifications, particularly on the latest rules, regulations, and fatwa, if any. Evidently, a research by Hassan, Arif and Sidek (2015) revealed that the implementation of Internal Halal Assurance System (IHAS) by halal executives is mainly based on their religious knowledge that they 
possess with insignificant attention given to the requirements of IHAS. Therefore, it is very important for members of IHC to be equipped with knowledge and skill through continuous training in halal standard and certification implementation. Together with that, it was recommended for the company to have memorandum of understanding (MOU) with universities and government agencies to share knowledge, skill, and expertise so that both can benefit from each other. The establishment of Centre of Excellence by local universities such as the Asian Halal Institute (AHAL) by Universiti Utara Malaysia (UUM), International Institute for Halal Research and Training (IIHRT) by International Islamic University Malaysia (IIUM), and Halal Science Centre by University of Cyberjaya may be seen as an opportunity for such academia-industry linkages.

Most importantly, since the review process is done periodically and the renewal of Halal Certification is on yearly basis, it is important for the IHC to continually maintain effective documentation and record for evidential purposes. The existing system may be enhanced and updated to meet the current legal needs and auditors' expectation. On top of that, it is for the management of the company to closely monitor hygiene and sanitation of the factory as these aspects are crucial in applying for a new or renewing existing halal certification.

\subsection{Conclusion}

Undoubtedly, the establishment of the IHC by the company plays crucial roles in implementing legal requirements on halal product and monitoring halal aspects. Even though modern machines and equipment are used by a company, particularly a big company, the slaughter still needs to be carried out manually by Muslim slaughterers as required by Syarak and laws. The existence of IHC in a big company, which consists of among others, the halal checker and accredited slaughterers, has proven that the company will not compromise on halal aspects of its production. This is mainly because the IHC will be answerable to JAKIM/JAIN which may result in the halal certification of the product to be denied or revoked, thus, affecting the business of the company. Together with the practising of Good Manufacturing Procedure (GMP) and Hazard Analysis Critical Control Point (HACCP), they have made the products produced by such a big company to be believed as being cleaner, having more quality, and guaranteed halal, as these aspects are thoroughly monitored by the enforcement agencies and industry through the establishment of the IHC.

\section{Acknowledgement}

The authors would like to note their highest appreciation to the Universiti Utara Malaysia generally and to the Institute for Management and Business Research 
(IMBRe) particularly for funding this research. The authors would also like to extend their appreciation to all related parties involved in completing this study including the respondents from Jimat Jaya Sdn. Bhd and Kedah Islamic Religious Affairs Department (JHEAIK).

\section{References}

Abdul Talib, H. H., \& Mohd Ali, K. A. (2009). An overview of Malaysian food industry: The opportunity and quality aspects. Pakistan Journal of Nutrition, 8, 507-517. https://scialert.ne t/fulltext/?doi=pjn.2009.507.517\&org=11.

Abdullah, A., Zubairi, S. I., \& Ghani, M. A. (2007, August). Halal food: Scenario and current status in Malaysia. Paper presented at the 10th ASEAN Food Conference 2007, KLCC, Malaysia. Retrieved from https://www.researchgate. net/publication/235352305_Halal_Food_Scenario_and_Current_Status_in_ Malaysia.

Cab.com (2020). CAB - A fully integrated poultry farming and food processing company. Retrieved from https://www.cab.com.my/home/.

Department of Islamic Development Malaysia (JAKIM). (2011). Malaysia guidelines on halal assurance management system 2011. Retrieved from http://www.halal. gov.my/v4/index.ph p?data=bW9kdWxlcy9uZXdzOzs7Ow==\&utama=pandua n\&ids $=$ gp3.

Department of Islamic Development Malaysia (JAKIM). (2015). Manual procedure for Malaysia halal certification (Third Revision) 2014. Selangor, Malaysia: Firdaus Press.

Descriptions (Definition of Halal) Order 2011.

Hassan, M.H., Arif, S., \& Sidek, S. (2015). Knowledge and practice for implementing internal halal assurance system among halal executives. Asian Social Science; 2(17), 57-66. http://dx .doi.org/10.5539/ass.v11n17p57.

Mian N. R., \& Munir, M. C. (2018). General guidelines for halal food production from: Handbook of halal food production. Retrieved from https://www. routledgehandbooks.com/doi/10.1201/9781315119564-3.

Razaly, M., \& Zakaria, Z. (2018). Pelaksanaan sistem pengurusan jaminan halal di rumah-rumah sembelihan ayam halal dan isu-isu berkaitan: Satu sorotan literatur. Journal of Shariah Law Research, 3(1), 105-124. https://doi. org/10.22452/http://doi.org/10.22452/JSLR.vol3no1.5.

Shafii, Z., \& Md Zain, S. N. (2015), Halal assurance mechanism in halal industry: An appraisal on its effectiveness towards continuous halal assurance and the way forward. Paper presented at the 2nd International Conference on Education and Social Sciences 2015, Istanbul, Turkey. Retrieved from https://pdfs. semanticscholar.org/aa15/ceaf4cffbdce126714981da33eb7c766a450.pdf?_ ga=2.166018494.1272651204.1597116100-2080962045.1597116100. 